\title{
Selective Spectrophotometric Method for the Hydrocortisone Butyrate Quantitative Determination in Compounding Ointment in Presence of Nitrofural and Procaine Hydrochloride
}

\author{
Lesia P. Savchenko ${ }^{1 *}$, Valentin O. Vrakin², Volodymyr O. Grudko ${ }^{2}$, Tetiana V. Krutskikh ${ }^{3}$, Volodymyr K. Yakovenko ${ }^{4}$, \\ Victoriya A. Georgiyants ${ }^{2}$ \\ ${ }^{1}$ Department of Quality, Standardization and Certification of Drugs, Institute of Pharmacy Professionals Qualification Improvem ent, National University of \\ Pharmacy, Kharkiv, Ukraine. ${ }^{2}$ Department of Pharmaceutical Chemistry, National University of Pharmacy, Kharkiv, Ukraine. ${ }^{3}$ Vice-Rector for scientific \\ work, National University of Pharmacy, Kharkiv, Ukraine. ${ }^{4}$ Department of Industrial Pharmacy and Economics, Institute of Pharmacy Professionals \\ Qualification Improvement, National University of Pharmacy, Kharkiv, Ukraine.
}

\begin{tabular}{|c|c|}
\hline ARTICLE INFO & ABSTRACT \\
\hline $\begin{array}{l}\text { Article history: } \\
\text { Received on: } 07 / 04 / 2017 \\
\text { Accepted on: } 13 / 06 / 2017 \\
\text { Available online: } 30 / 08 / 2017\end{array}$ & $\begin{array}{l}\text { Methods of sample preparation for the hydrocortisone butyrate excretion from compounding ointment were } \\
\text { studied. The new procedure for its quantitative determination by spectrophotometry in the presence of nitrofural } \\
\text { and procaine hydrochloride was developed during the research process. It is based on the hydrocortisone } \\
\text { butyrate ability to interact with phenylhydrazyne with forming a phenylhydrazone, which has a maximum }\end{array}$ \\
\hline $\begin{array}{l}\text { Key words: } \\
\text { Compounding ointment, } \\
\text { hydrocortisone butyrate, } \\
\text { quantitative determination, } \\
\text { spectrophotometry. }\end{array}$ & $\begin{array}{l}\text { other ointment components. The total uncertainty of analysis, the parameters of linearity, accuracy and precision } \\
\text { were calculated. The recovery of hydrocortisone butyrate was found to be } 100.82 \% \text {. The correlation coefficient } \\
\text { was found to be } 0.9995 \text {. The validation of the developed method proves its specificity and accuracy and allows } \\
\text { recommending it for the hydrocortisone butyrate quantitative determination in the presence of procaine and } \\
\text { nitrofural. }\end{array}$ \\
\hline
\end{tabular}

\section{INTRODUCTION}

In the middle of the XX century corticosteroids were recommended for the treatment of dermatological diseases for the first time. From those times, they have become essential drugs due to their anti-inflammatory, antiallergic and anti-

\footnotetext{
* Corresponding Author

Lesia P. Savchenko, Department of Quality, Standardization and Certification of Drugs, Institute of Pharmacy Professionals Qualification Improvement, National University of Pharmacy, Kharkiv, Ukraine. Email: savchenkolesia@gmail.com
}

proliferative effects (Goryachkina et al., 2009, Hengge et al., 2006, Monakhov et al., 2008). The presence of side effects in the first corticosteroids led to the researches for the development of more advanced analogues. It was found that the introduction of substitutes in certain positions allows to modify the strength and action direction of pharmacologically active substances of this group (Hengge et al., 2006, Monakhov et al., 2008). The presence of a keto- or a hydroxyl group at the 11 positions and a hydroxyl group at 17 position of the steroid cycle is responsible for glucocorticoid activity of corticosteroids. Halogenation at the 9 position enhances the potency of action by increasing activity within the target cell and reducing the rate of decomposition into inactive metabolites. 
The placement of substitute at 16 position practically eliminates mineralocorticoid activity and esterification at 17 or 21 positions by fatty acids increases most topical activity of corticosteroids. The formation of cyclic acetonides at the 16 or 17 positions with fluorine atoms at positions 6 and 9 leads to the topical anti-inflammatory activity usually without increasing of glucocorticoid activity (Hengge et al., 2006, Tolba et al., 2015).

One of corticosteroid drugs that are widely used in medical practice in Ukraine and foreign countries is hydrocortisone-17-butyrate (Fig. 1).

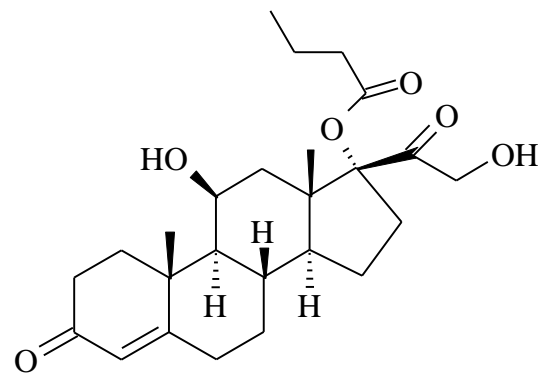

A

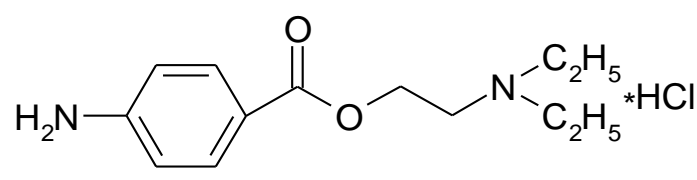

B

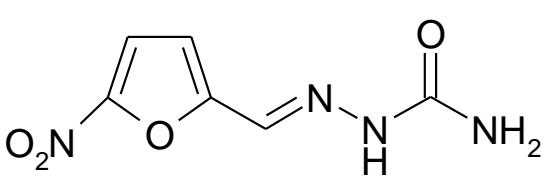

$\mathrm{C}$

Fig. 1: Structure of hydrocortisone-17-butyrate (a), procaine hydrochloride (b) and nitrofural (c).

It belongs to the III class glucocorticoids with an average potency of action and produces as an ointment, cream, Lipocream, emulsion or solution. The introduction of the butyric acid to the hydrocortisone molecule enhanced the lipophilicity of the substance and its penetration into the skin. In addition, on the substance activity the kind of dosage form influences. Thus, the hydrocortisone butyrate ointment shows the strongest action (Goryachkina et al., 2009, Monakhov et al., 2008, PL DetailDocument, 2012).

Despite some advantages, hydrocortisone butyrate applying has contraindications in which its application in treatment is undesirable. This applies particularly to dermatoses with bacterial and viral component, skin damage caused by yeast or other fungi. Moreover, dermatoses often have several reasons that cause the necessity of different direction of the active pharmaceutical ingredients (API) actions at the same time. One of the methods of expanding the action range of drugs with glucocorticoids is their combination with antibacterial agents. There are many multicomponent ointments which containing glucocorticoids in combination with antibacterial and antifungal components in the pharmaceutical market of Ukraine. They include betamethasone in combination with gentamicin, clotrimazole, miconazole and hydrocortisone acetate in combination with chloramphenicol, oxytetracycline or fuzidic acid. Their main disadvantage is the inability of individual dosing and replacement of certain drug component because of individual sensitivity to it. The solution of this situation is the possibility of preparing required compounding medicines.

One of these medicines, which are in demand in the treatment of dermatology diseases is compounding ointment, which is preparing on the basis of hydrocortisone industrial ointment with the addition of nitrofural (fig. 1, c) and procaine hydrochloride (fig. 1, b). Nitrofural complements the ointment action with antibacterial effect, inhibits the activity of fungal flora and promotes wound healing. Procaine hydrochloride reduces sensitivity in the place of application and reveals membrane stabilizing activity. In addition, compounding ointments made on the industrial basis ointments are technologically simple in preparation and provide good absorption of APIs through a well composed industrial ointment basis.

The existing methods of hydrocortisone butyrate quantitative determination do not allow its accurate determination in the presence of procaine hydrochloride and nitrofural. The aim of the study was to develop the hydrocortisone butyrate quantitative determination method by spectrophotometry in compounding ointment with nitrofural and procaine hydrochloride that could be used for its analysis in pharmacies and quality control laboratories. As a result of work, it is planned to develop and validate a procedure that succeeded to analyze hydrocortisone without interferences from the other components.

\section{MATERIALS AND METHODS}

Volumetric glassware of class A, spectrophotometer Evolution 60s (USA) with $1 \mathrm{~cm}$ cell, hydrocortisone butyrate standard (series $040 \mathrm{H} 0863 \mathrm{~V}$, produced by SIGMA ALDRICH, USA), procaine hydrochloride substance (series 140716, produced by Guanxi Shengtai Chemical Co., Ltd, China), nitrofural substance (series 20130319, produced by Jinan Jinda Pharmaceutical Chemistry Co., Ltd, China), hydrocortisone $1 \%$ ointment (series 110516, produced by "Nizhpharm", Russia) were used for work with the compounding ointment on their basis by the following composition:

$$
\begin{array}{ll}
\text { Rp.: } & \text { Furacillini } 0.02 \\
& \text { Novocaini } 0.1 \\
& \text { Ung. Hydrocortisoni } 1 \%-10.0 \\
& \text { M. D. S. }
\end{array}
$$

All other reagents were of analytical grade.

\section{Method of hydrocortisone butyrate excretion modified by reaction on unsaponifiable matters.}

To $1 \mathrm{~g}$ of ointment were added $10 \mathrm{ml}$ of ethanol (96 per cent), heated until the base melted, cooled and transferred into a 50 
$\mathrm{ml}$ volumetric flask. The operation was repeated four times with 5 $\mathrm{ml}$ of ethanol (96 per cent). Volume was diluted to mark $50 \mathrm{ml}$ with ethanol (96 per cent) (dilution A). $5 \mathrm{ml}$ of dilution A was placed into a $25 \mathrm{ml}$ volumetric flask, diluted to mark $25 \mathrm{ml}$ with chloroform. $20 \mathrm{ml}$ of $0.1 \mathrm{M}$ potassium hydroxide solution and 10 $\mathrm{ml}$ of chloroform dilution were placed on separating funnel. The mixture was shaken and allowed to settle. The chloroform layer was separated. Repeat the procedure with $15 \mathrm{ml}$ of chloroform dilution and $20 \mathrm{ml}$ of $0.1 \mathrm{M}$ potassium hydroxide solution. Chloroform layer was washed with three portions of $20 \mathrm{ml}$ of water R. Chloroform extract placed into the evaporation cup, chloroform was evaporated.

A quantitative determination by spectrophotometry was conducted by two ways.

a) The residue was quantitatively transferred by three portions of ethanol $10 \mathrm{ml}$ each (96 per cent) into a $100 \mathrm{ml}$ volumetric flask and diluted to the mark with the same solvent. Reference solution - ethanol (96 per cent).

b) The residue was quantitatively transferred by three portions of sulphuric acid $10 \mathrm{ml}$ each into a $100 \mathrm{ml}$ volumetric flask and diluted to the mark with the same solvent. Reference solution - sulphuric acid.

\section{Method of hydrocortisone butyrate quantitative determination of reaction with sulphuric acid after isolation with ethyl acetate}

To $1 \mathrm{~g}$ of ointment $10 \mathrm{ml}$ of methanol was added and heated until the base melted, mixed, cooled and carefully decanted solution into a $25 \mathrm{ml}$ volumetric flask. The operation was repeated twice with $6 \mathrm{ml}$ of methanol. The solution was diluted to the mark $25 \mathrm{ml}$ with the same solvent. The solution was filtered (dilution B). $1 \mathrm{ml}$ of dilution B was placed into a separating funnel, $20 \mathrm{ml}$ of ethyl acetate was added and separation of nitrofural and procaine hydrochloride with four portions of $10 \mathrm{ml}$ of isotonic sodium chloride solution was conducted. The water layer was rejected, ethyl acetate evaporated and the residue was quantitatively transferred into a $10 \mathrm{ml}$ volumetric flask with three portions of 2 $\mathrm{ml}$ of sulfphuric acid and diluted to the mark with the same solvent. Conduct a quantitative determination of hydrocortisone butyrate by spectrophotometry.

Reference solution - sulphuric acid.

\section{Method of hydrocortisone butyrate quantitative determination with a solution of iron (III) chloride and potassium hexacyanoferrate (III)}

$10 \mathrm{ml}$ of dilution A was evaporated more than a half, placed in a $10 \mathrm{ml}$ volumetric flask, $2 \mathrm{ml}$ of iron (III) chloride $0.5 \%$ solution, $2 \mathrm{ml}$ of $2 \mathrm{M}$ sulphuric acid and $0.5 \mathrm{ml}$ of potassium hexacyanoferrate (III) $0.5 \%$ solution were added (Singh et al., 2008). The mixture was heated on a water-bath at $70{ }^{\circ} \mathrm{C}$ for 30 minutes, cooled and diluted to the mark with distilled water.

Reference solution: $5.5 \mathrm{ml}$ of ethanol (96 per cent) was placed into a $10 \mathrm{ml}$ volumetric flask, $2 \mathrm{ml}$ of iron (III) chloride $0.5 \%$ solution, $2 \mathrm{ml}$ of $2 \mathrm{M}$ sulphuric acid and $0.5 \mathrm{ml}$ of potassium hexacyanoferrate (III) $0.5 \%$ solution were added (Singh et al., 2008). The mixture was heated on a water-bath at $70{ }^{0} \mathrm{C}$ for 30 minutes, cooled and diluted to the mark with distilled water.

The quantitative determination was performed with the control experiment.

\section{Method of hydrocortisone butyrate quantitative determination with phenylhydrazine.}

Preparation of the phenylhydrazine solution: to $62 \mathrm{ml}$ of sulphuric acid $38 \mathrm{ml}$ of methanol and $65 \mathrm{mg}$ of phenylhydrazine were added.

Tested solution. $1 \mathrm{ml}$ of dilution B placed in a $25 \mathrm{ml}$ volumetric flask, $1 \mathrm{ml}$ of phenylhydrazine solution and $9 \mathrm{ml}$ of sulphuric acid were added. Reference solution: $1 \mathrm{ml}$ of dilution B was placed into a $25 \mathrm{ml}$ volumetric flask, $10 \mathrm{ml}$ of sulphuric acid was added. The mixtures were simultaneously heated on a waterbath at $60{ }^{\circ} \mathrm{C}$ for 30 minutes, cooled and diluted to the mark $25 \mathrm{ml}$ with glacial acetic acid.

The standard solution. $0.4 \mathrm{~g}$ of hydrocortisone butyrate was placed into a $1000 \mathrm{ml}$ volumetric flask, dissolved in methanol, diluted to the mark with the same solvent and mixed (dilution $\mathrm{C}$ ). $1 \mathrm{ml}$ of dilution $\mathrm{C}$ was placed into a $25 \mathrm{ml}$ volumetric flask, $1 \mathrm{ml}$ of phenylhydrazine solution and $9 \mathrm{ml}$ of sulphuric acid were added. Reference solution: $1 \mathrm{ml}$ of dilution $\mathrm{C}$ was placed into a 25 $\mathrm{ml}$ volumetric flask, $10 \mathrm{ml}$ of sulphuric acid was added. The mixtures were simultaneously heated into a water-bath at $60{ }^{\circ} \mathrm{C}$ for 30 minutes, cooled and diluted to the mark $25 \mathrm{ml}$ with glacial acetic acid.

Blanc solution (for measurement of excipients impact on the quantitative determination results). $1 \mathrm{ml}$ of methanol was placed into a $25 \mathrm{ml}$ volumetric flask, $1 \mathrm{ml}$ of phenylhydrazine solution and $9 \mathrm{ml}$ of sulphuric acid were added. Reference solution: $1 \mathrm{ml}$ of methanol was placed into a $25 \mathrm{ml}$ volumetric flask, $10 \mathrm{ml}$ of sulphuric acid was added. The mixtures were simultaneously heated on a water-bath at $60{ }^{\circ} \mathrm{C}$ for 30 minutes, cooled and diluted to the mark $25 \mathrm{ml}$ with glacial acetic acid.

\section{RESULTS AND DISCUSSION}

\section{Method development}

One of the main reaction of corticosteroids quantitative determination is based on the ability of $\alpha$-keto group oxidation with triphenyltetrazolium chloride alcoholic solution in the presence of tetramethylammonium hydroxide solution with the formation of red farmazones (Singh et al., 2008). Due to the presence of keto group in 3 position the steroids can interact with isoniazide and phenylhydrazine with formation of colored solutions.

Articles "Hydrocortisone butyrate" contain the Japanese (The Japanese Pharmacopoeia. 2007), Chinese (Pharmacopoeia of the People's Republic of China, 2005) Pharmacopoeias and USP (The United States Pharmacopoeia, 2007). SPhU includes only the article "Hydrocortisone Acetate", which recommends its quantitative determination of liquid chromatography method (State 
Pharmacopoeia of Ukraine, 2014). Japanese Pharmacopoeia recommends conducting hydrocortisone butyrate quantitative determination by Ultraviolet-visible spectrophotometry after dissolving in ethanol at the wavelength $241 \mathrm{~nm}$ (The Japanese Pharmacopoeia, 2007). Quantitative determination in the Chinese Pharmacopoeia is conducted by the method of HPLC with detection at $240 \mathrm{~nm}$ wavelength. Except the article on the substance, Chinese Pharmacopoeia contains the article "Hydrocortisone butyrate cream" which also recommends using HPLC for its quantitative determination (Pharmacopoeia of the People's Republic of China, 2005). According to the USP for quantitative determination of the hydrocortisone butyrate substance and cream used HPLC with detection at wavelength 254 $\mathrm{nm}$ (after dissolution in a mixture of tetrahydrofuran and glacial acetic acid) (The United States Pharmacopoeia, 2007). In view of the existing information, our goal was to develop new hydrocortisone butyrate quantitative determination method in the studied compounding ointment taking into account the nitrofural and procaine influence on the analysis results.

As nitrofural absorbance maxima (260 and $375 \mathrm{~nm}$ ) (State Pharmacopoeia of Ukraine, 2014) and procaine hydrochloride (222 and $290 \mathrm{~nm}$ ) maxima (Georgiyants et al., 2007) are close to the hydrocortisone butyrate absorbance maxima, at first, we decided to develop a scheme of hydrocortisone butyrate excretion from the studied compounding ointment with the ability of its full separation from nitrofural and procaine hydrochloride. Hydrocortisone butyrate freely soluble in tetrahydrofuran, in chloroform and in 1,2-dychloroethane, soluble in methanol, sparingly or soluble in ethanol, slightly soluble in diethyl ether, practically insoluble in water (The Japanese Pharmacopoeia. 2007, Pharmacopoeia of the People's Republic of China, 2005, The United States Pharmacopoeia, 2007). Nitrofural very slightly soluble in water, slightly soluble in ethanol, procaine hydrochloride very soluble in water, soluble in ethanol (State Pharmacopoeia of Ukraine, 2014).

For hydrocortisone butyrate separation from nitrofural and procaine hydrochloride was used alkaline hydrolysis reaction as in unsaponifiable matters determining which was modified. Potassium hydroxide solution which is used in this reaction allows separating nitrofural which is easily soluble in an alkaline solution and procaine hydrochloride, able to hydrolysation in an alkaline environment from hydrocortisone butyrate. Laundering with water is used during the analysis, which additionally promotes the component separation. As diethyl ether which is recommended for use in the excretion refers to the precursors, it was replaced by chloroform. Moreover, hydrocortisone butyrate more soluble in chloroform than in diethyl ether, procaine hydrochloride and nitrofural are practically insoluble in it. After the excretion hydrocortisone butyrate residue was dissolved in ethanol (96 per cent) (a) or sulphuric acid (b) and quantitative determination by spectrophotometry was conducted. The using of sulphuric acid allows to transfer hydrocortisone butyrate absorption maximum to near ultraviolet region where the absorption of other APIs and excipients is insignificant and has no effect on the results of hydrocortisone butyrate quantitative determination. This method of component separation was refused because, despite a few stages of cleaning, a certain amount of nitrofural and procaine hydrochloride remains in the final solution and interfere with the hydrocortisone butyrate quantitative determination results.

Due to the possibility of hydrocortisone butyrate dissolving in ethyl acetate was decided to try to use it to separate of the ointment components. For the nitrofural and procaine hydrochloride separation isotonic sodium chloride solution was used. After the excretion of hydrocortisone butyrate from the ointment its quantitative determination by spectrophotometry based on the reaction with sulphuric acid was conducted. The results showed the impossibility of such ointment components separation process and using it for hydrocortisone butyrate quantitative determination, because by this way is impossible to separate nitrofural and procaine hydrochloride completely, which prevent analysis conducting.

Whereas being unable to achieve complete components separation, it was decided to develop a method that would allow to conduct hydrocortisone butyrate quantitative determination in the presence of nitrofural and procaine hydrochloride. Photocolorimetric method with oxidation of hydrocortisone butyrate was used for this. Owing to the presence of $\alpha$-keto group, Indian scientists offered the reaction of corticosteroids quantitative determination by spectrophotometry based on the reaction with solutions of iron (III) chloride and potassium hexacyanoferrate (III). As a result of reaction the bluish-green complex with a maximum absorption at $780 \mathrm{~nm}$ produces (Singh et al., 2008). The method is quite simple and fast. It was used for development of hydrocortisone butyrate quantitative determination method in compounding ointment. During the researches was found that measuring the absorbance preferably to conduct after solution cooling for 15 minutes because immediately after the value of optical density is increasing. The research of linearity has shown the possibility of this method using for the hydrocortisone butyrate quantitative determination in substance. To verify the possibility of a reaction using for ointment analysis model's mixtures with nitrofural and procaine hydrochloride were made, in each of them solutions of hydrocortisone butyrate, iron (III) chloride and potassium hexacyanoferrate (III) were added with followed by spectrophotometric determination. Studies have shown the presence of maximum absorption at $456 \mathrm{~nm}$ and proved that nitrofural and procaine hydrochloride are interfering with the hydrocortisone butyrate quantitative determination in the ointment of this method. This can be explained by using of potassium hexacyanoferrate (III), which is quite strong non-specific oxidizer, so it can react with all API of the dosage form.

The presence of keto-group in 3 position causes the possibility of conducting the hydrocortisone butyrate quantitative determination of the reaction with phenylhydrazine. For increasing solution color stability to the resulting ointment extract glacial acetic acid was added. The optical density was measured in 30 minutes after preparation of the test solutions, as it continued to grow until that time. 


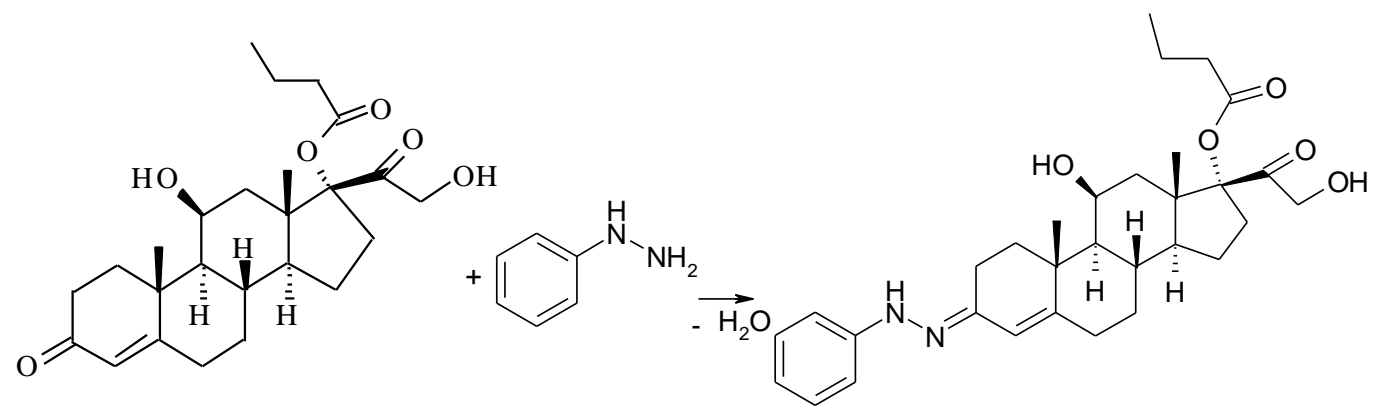

Fig. 2: Formation of hydrocortisone-17-butyrate phenylhydrazone.

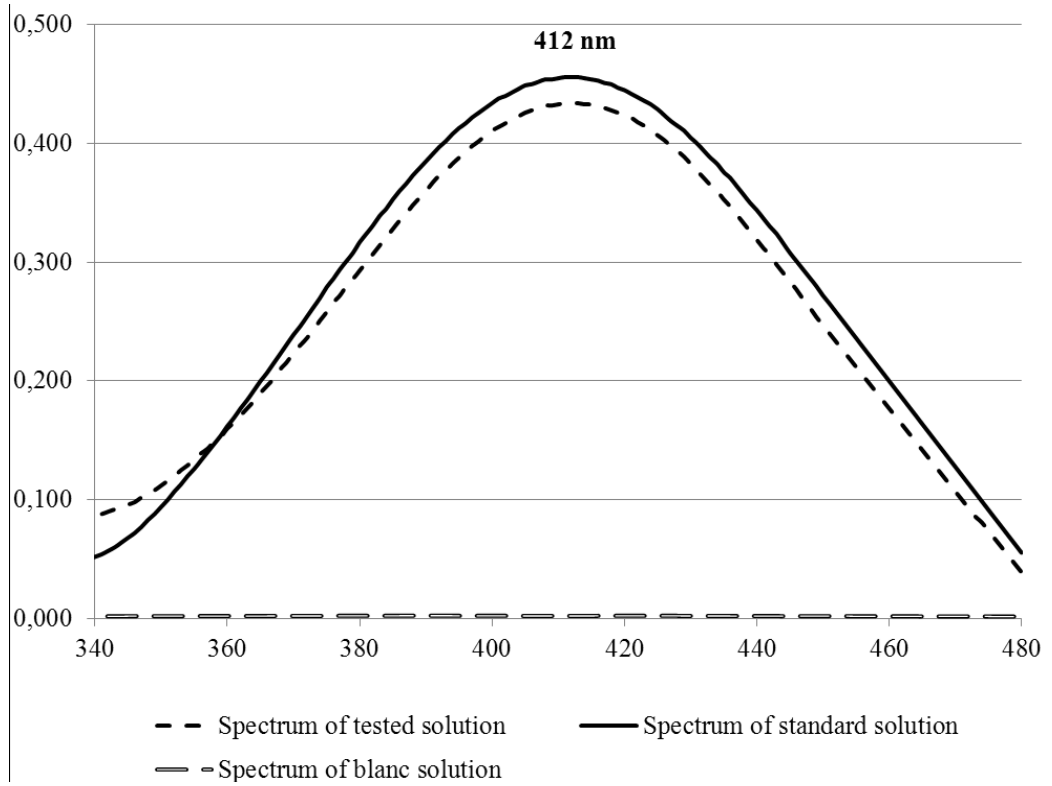

Fig. 3: UV spectrum of hydrocortisone butyrate quantitative determination (in concentration of $1.6 X_{10^{-5} \mathrm{~g} / \mathrm{ml} \text { ) }}$ in compounding ointment with spectra of standard and blank solutions.

Hydrocortisone butyrate reacts with phenylhydrazyne by forming a phenylhydrazone (Fig. 2), which has a maximum absorption at $412 \mathrm{~nm}$ (Fig. 3). As seen from the structure of nitrofural (fig. 1, c) and procaine hydrochloride (fig. 1, b), they will not enter into this reaction. During developing quantitative determination methods for the test and standard solutions reference solutions without adding phenylhydrazine solution were made. The presence of all other components in them during the quantitative determination allows to determine only color caused by the formation of hydrocortisone butyrate phenylhydrazone and to compensate absorption caused by the nitrofural, procaine hydrochloride and excipients presence. The quantitative determination was performed by the method of standard. We recommend this reaction for the hydrocortisone butyrate quantitative determination in compounding ointment.

\section{Validation of the method.}

For proving the possibility of the method using for ointment analysis, it was validated according to the article 5.3.N.2.
Validation of analytical methods and tests requirements of the SPhU (State Pharmacopoeia of Ukraine, 2015). For the ointment analysis, we used hydrocortisone butyrate concentration of $1.6 \times$ $10^{-5} \mathrm{~g} / \mathrm{ml}$.

Maximum acceptable uncertainty of the analysis results was calculated before the study due to tolerance deviations of components quantitative content in compounding ointment according to the $\operatorname{SPhU}( \pm 10 \%)$ : $\max \Delta_{\mathrm{As}}=10 \times 0.32=3.2 \%$.

Evaluation of sample preparation uncertainly $\left(\Delta_{\mathrm{SP}}\right)$ which took into account all stages of weighing and dilution was made before the analysis (Table 1). During choosing samples and aliquots the value of the glassware uncertainty was taken into account to reduce the overall error of study solutions preparation.

The calculated sample preparation uncertainty is $1.12 \%$ and it is insignificant compared to the total uncertainty of the analysis $\left(\Delta_{\mathrm{As}}\right)$. The relation $\Delta_{\mathrm{SP}} \leq 0.32 \times \Delta_{\mathrm{As}}=1.024 \%$ is not satisfied because the main source of the spectrophotometric methods uncertainty is sample preparation. 
Total uncertainty of this method analysis will constitute:

$$
\Delta_{A s}=\sqrt{\Delta_{F A O}^{2}+\Delta_{S P}^{2}}=\sqrt{0.70^{2}+1.12^{2}}=1.32 \% .
$$

It is not exceeding max $\Delta_{\mathrm{As}}$, which indicates that the method will give correct results in other laboratories.

The specificity $\left(\delta_{\text {noise }}, \%\right)$ of this method was studied. It describes excipients and possible decomposition product's effect on the results of the quantitative determination of investigating component. Blank solutions with and without phenylhydrazine were made during working out the method. The average value of the placebo solution $\left(A_{\text {blanc }}=0.0024\right)$ and reference solution $\left(A_{s t}=0.585\right)$ absorbances were found. The relative systematic error caused by excipients will constitutes:

$$
\delta_{\text {noise }}=\mathrm{A}_{\text {bland }} / \mathrm{A}_{\mathrm{st}} \times 100=0.41 \% \text {. }
$$

This value is insignificant compared with the maximum relative systematic error $0.41 \% \leq \max \delta \leq 1.024 \%$.

All necessary validation characteristics: linearity, accuracy and precision were examined during validation conducting. The study of linearity was conducted in the concentration range $80-120 \%$ of the substance nominal concentration. 9 model solutions of 9 concentrations with a step of $5 \%$ were analyzed. Absorbance measurements were performed three times with removing the cuvette for each of the 9 solutions. Parameters which characterizing linear dependence (Table 2) were calculated - corner coefficient, constant term of the linear dependence, the residual standard deviation, correlation coefficient.

Table 2: Results of the linear dependence parameters study of hydrocortisone

\begin{tabular}{|c|c|}
\hline Validation characteristics & The obtained value \\
\hline$b$ & 1.0084 \\
\hline$S_{b}$ & 0.0066 \\
\hline$(b-1)$ & 0.0084 \\
\hline$a$ & 0.1583 \\
\hline$S_{a}$ & 0.6662 \\
\hline \multicolumn{2}{|c|}{$\begin{array}{l}\text { The criterion of } a \text { statistical insignificance } \\
\left(a \leq t(95 \%, n-2) \times S_{a}\right)\end{array}$} \\
\hline \multicolumn{2}{|c|}{$0.1583 \leq 1.1379$} \\
\hline$S_{0}$ & 0.4432 \\
\hline \multirow{3}{*}{\multicolumn{2}{|c|}{$\begin{array}{l}\text { Requirements for the residual standard deviation } \\
\qquad S_{0} \leq \frac{\Delta_{A s}(\%)}{t(95 \%, n-2)}=1.55\end{array}$}} \\
\hline & \\
\hline & \\
\hline$r$ & 0.9995 \\
\hline $\begin{array}{l}\text { The critical value of the } \\
\qquad S_{Y}, \%\end{array}$ & $\begin{array}{c}\text { fficient }(\min r): R_{c} \geq 0,9898 \\
13.1559\end{array}$ \\
\hline
\end{tabular}
butyrate quantitative determination method by spectrophotometry.

The obtained values are showing that the coefficient $b$ is close to 1 , the requirements to statistical insignificance of the constant term of the linear dependence $a$ are executed. The residual standard deviation does not exceed its confidence interval; the requirements to the correlation coefficient are executed too.

Following the results of the study linear calibration graph in normalized coordinates was built (Fig. 4).

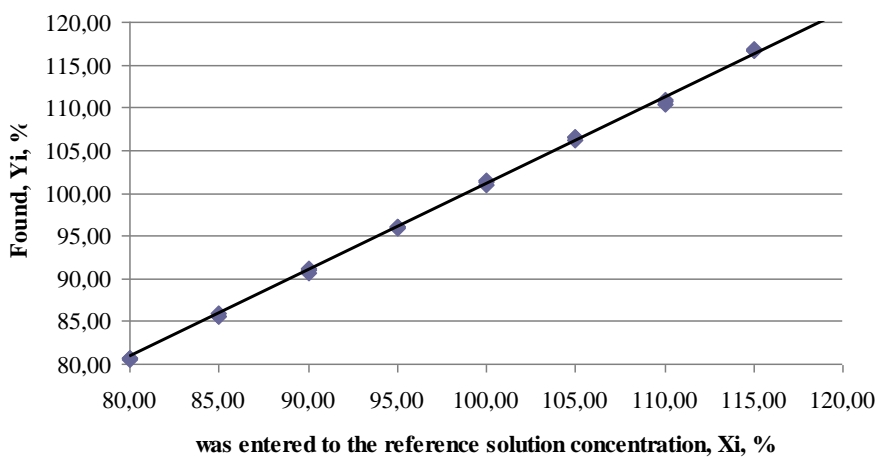

Fig. 4: Graph of the linear dependence of optical density of the hydrocortisone butyrate concentration in normalized coordinates

The study of accuracy and precision by using the data obtained in the method linearity study were conducted simultaneously with the study of linearity by standardized procedure (Table 3).

Table 3: Results of the precision and accuracy study of hydrocortisone butyrate quantitative determination method by spectrophotometry.

\begin{tabular}{cc}
\hline Validation characteristics & The obtained value \\
\hline $\bar{Z}$ & 100.99 \\
$S_{Z}$ & 0.07739 \\
$\Delta_{\mathbf{Z}}$ & 0.132 \\
\hline $\boldsymbol{\delta}$ & 0.99 \\
\hline Criterion of one-sided confidence interval $\Delta_{\mathrm{Z}} \leq \Delta_{\mathrm{As}}(0.132 \leq 3.2)$ \\
\hline Criterion of statistical insignificance $\delta, \% \leq 0.025$ \\
\hline
\end{tabular}

Accuracy is characterized by systematic error $\delta$. Its statistical insignificance criterion has not executed, but its practical insignificance criterion has performed that meets the requirements. The requirements for the method precision have performed as $\Delta_{\mathrm{Z}}$ is much smaller than $\Delta_{\text {As }}$. The recovery of the method was studied by analyzing five different concentrations (corresponding to 80 , $90,100,110$ and $120 \%$ of the test preparation concentration). The summary of the results and average mean of recovering data are shown in table 4.

Table 4: Results from study of hydrocortisone butyrate recovery in the presence of procaine and nitrofural.

\begin{tabular}{cccc}
$\begin{array}{c}\text { Theoretical } \\
\text { concentration } \\
\text { \% }\end{array}$ & $\begin{array}{c}\text { Concentration } \\
\text { found, \% }\end{array}$ & $\begin{array}{c}\text { Recovery of } \\
\text { hydrocortisone } \\
\text { butyrate, \% }\end{array}$ & $\begin{array}{c}\text { Mean of recovering } \\
\text { of hydrocortisone } \\
\text { butyrate, \% }\end{array}$ \\
\hline \multirow{2}{*}{80.00} & 80.68 & 100.85 & 100.78 \\
& 80.51 & 100.64 & 100.98 \\
90.00 & 80.68 & 100.85 & \\
& 90.94 & 101.04 & 101.31 \\
100.00 & 90.60 & 100.66 & 100.65 \\
& 91.11 & 101.23 & \\
\hline \multirow{2}{*}{110.00} & 101.37 & 101.37 & 100.38 \\
& 101.03 & 101.03 & \\
\hline \multirow{2}{*}{120.00} & 101.54 & 101.54 & \\
& 110.77 & 100.70 & \\
\hline
\end{tabular}




\section{CONCLUSION}

The spectrophotometric method was developed for quantitative determination of hydrocortisone butyrate in compound ointment in the presence of nitrofural and procaine hydrochloride. Further, the validation characteristics of the developed method were studied. Parameters of linearity, accuracy and precision indicate the correctness of the method and the possibility of its use in other laboratories for analysis of hydrocortisone butyrate in the studied compounding ointment in the procaine and nitrofural presence.

\section{Financial support and sponsorship: Nil.}

Conflict of Interests: There are no conflicts of interest.

\section{REFERENCES}

Georgiyants VA, Evtifeyeva OA, Savchenko LP, Bisaga EI. Using of the spectrophotometric method for the quantitative determination of procaine hydrochloride in the extemporaneous preparation. Zaporozh. Med. J., 2007; 2:129-133.

Goryachkina MV, Belousova TA. Rational choice of topical glucocorticosteroid in the treatment of inflammatory dermatoses. Dermatology, 2009; 1:3-8.

Hengge UR, Ruzicka T, Schwartz RA, Cork MJ. Adverse effects of topical glucocorticosteroids. J. Am. Acad. Dermatol., 2006; 54 (1):1-15.

Monakhov SA, Ivanov OL. Modern principles of treatment of patients with inflammatory diseases experience of using hydrocortisone 17-butyrate ointment (Locoid). Ukr. J. of Dermatol., Venerol., Cosmetol., 2008; 1:54-58.

Pharmacopoeia of the People's Republic of China. 2005. Chinese Pharmacopoeia Comission: People's Medical Publishing House, Vol. II, $1104 \mathrm{p}$.

PL Detail-Document № 280908. 2012. Comparison of Topical Corticosteroids. Stockton: Therapeutic Research Center, 1-12.
Singh DK, Verma R. Spectrophotometric determination of corticosteroids and its application in pharmaceutical formulation. Iranian J. of Pharmacol. and Therap., 2008; 7:61-65.

State Pharmacopoeia of Ukraine: at 3 volumes. 2014. Kharkiv: State enterprise "Ukrainian scientific pharmacopoeial center of medicines quality", 2-nd ed., Vol. 2, 724 p.

State Pharmacopoeia of Ukraine: at 3 volumes. 2015. Kharkiv: State enterprise "Ukrainian scientific pharmacopoeial center of medicines quality", 2-nd ed., Vol. 1, 1128 p.

The Japanese Pharmacopoeia. 2007. The National Institute of Health Sciences: 15-th ed., $1788 \mathrm{p}$

The United States Pharmacopoeia. 2007. Rockville: The United State Pharmacopeial, XXX ed., 3503 p.

Tolba EHM, El-Bagary RI. 2015. Development and Validation of New Analytical Methods for the Determination of Some Steroidal Drugs. Cairo University: Faculty of Pharmacy, 1-33.

\section{How to cite this article:}

Savchenko LP, Vrakin VO, Grudko VO, Krutskikh TV, Yakovenko VK, Georgiyants VA. Selective Spectrophotometric Method for the Hydrocortisone Butyrate Quantitative Determination in Compounding Ointment in Presence of Nitrofural and Procaine Hydrochloride. J App Pharm Sci, 2017; 7 (08): 062-068. 